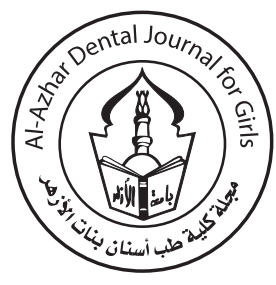

\title{
Evaluation of the Adhesion of Streptococcus Mutans to Different Orthodontic Arch Wires and the Effect of Honey Mouth Wash on it
}

\author{
Alaa M. Eldriny ${ }^{1 *}$, Samir A. Ibrahim ${ }^{2}$, Fatma A. Abdel Samad ${ }^{2}$, Haneya A. Ali ${ }^{3}$
}

Codex : 80/20.10

azhardentj@azhar.edu.eg

http://adjg.journals.ekb.eg

DOI: $10.21608 /$ adjg.2020.17843.1198

Pediatric Dentistry \& Orthodontics ( Pediatric Dentistry, Orthodontics)

\begin{abstract}
Purpose: To compare the adhesion of Streptococcus Mutans to different orthodontic arch wires and also to determine the role of honey as mouth wash during orthodontic treatment. Materials and methods: 21 female orthodontic patients their age ranges from18-23 were participated in this study. Nitinol and Stainless steel half arch wires were inserted separately on each half of maxillary arch (split mouth design) for 90 minute before using honey mouth wash, then for another 90 minute 3, 7, 14 and 30 days after using honey mouth wash 2 times per day. On each time, samples of wires which about $10 \mathrm{~mm}$ from the distal part of each wire were been cut. The wire samples were placed on Eppendorf tubes and cultured on Mitis Salivarius media in the candle jar 5-10\% $\mathrm{CO}_{2}$ at $37^{\circ} \mathrm{C}$ for 2-3 days. Then the amount of Streptococcus Mutans adhesion were measured by Counting of colony forming units Results: Streptococcus Mutans adhesion were higher on Stainless steel wires than Nitinol wires and also were lower at both wires after using honey mouthwash. Statistical analysis revealed that there was a statistically significant difference between Stainless steel and Nitinol wires and after use of honey mouthwash $(\mathrm{P}<0.05)$. Conclusion: Streptococcus Mutans adhesion was higher on Stainless steel wires than Nitinol wires. Honey can be used as a natural antibacterial mouthwash during orthodontic treatment and also should be supported by other studies.
\end{abstract}

\section{INTRODUCTION}

Nowadays more people are seeking for orthodontic treatment to have beautiful and healthy smile but placement of orthodontic ap-

pliances like brackets and arch-wires inhibit the maintenance of a
Streptococcus Mutans,

Stainless steel, Nitinol, honey.

- Paper extracted from Master Thesis Titled" Evaluation of the Adhesion of Streptococcus Mutans to Different Orthodontic Arch Wire and the Effect of Honey Mouth Wash on it"

1. Demonstrator of Orthodontics, Faculty of Dental Medicine, for Girls, Al-Azhar University, Cairo, Egypt

2. Professor of Orthodontics, Faculty of Dental Medicine, for Girls, Al-Azhar University, Cairo, Egypt

3. Assistant Professor of Microbiology Department, Faculty of Medicine, for Girls Al-Azhar University, Cairo, Egypt

* Corresponding author email: alaamossad89@gmail.com 
proper oral hygiene and interfere with efficient tooth brushing. This increases the amount of oral colonization by cariogenic and periodontal pathogenic bacteria cause subsequent side effects such as gingival inflammation and white spot lesions ${ }^{(1,2)}$.

Arch wires could play an important role in demineralization of enamel during orthodontic treatment ${ }^{(3)}$.Placement of orthodontic appliances leads to increases in number of cariogenic streptococci, and after removal of the appliance their number return back to normal ${ }^{(4-6)}$.

Stainless-steel (SS) and nickel-titanium (NiTi) wires are the most common used arch wires on leveling and alignment of teeth, With the rise in bacterial resistance to antibiotics, there is much interest in the development of herbal and natural antimicrobials Honey is defined as a sweet liquid substance produced by bees. It has been shown to have antimicrobial activity and thus inhibit the growth of a wide range of bacteria, fungi and viruses ${ }^{(7-10)}$

Among the possible anti-microbial mechanisms the presence of inhibitory factors such as flavonoids, $\mathrm{H} 2 \mathrm{O} 2$, low $\mathrm{pH}$ and high osmolality $^{(11,12)}$. Allah and His messenger (peace be upon him), told us that honey can heal a variety of medical problems.

\section{MATERIALS AND METHODS}

\section{Patient's selection:}

This study was conducted on female orthodontic patients $(n=21,18-23$ years of age $)$ patients from those attending the outpatient clinic, Department of Orthodontics, Faculty of Dental Medicine, AlAzhar University For Girls.

\section{Inclusion criteria:}

All patients have good oral hygiene, highly motivation and cooperation and no use of any medication during the period of the study.

\section{Methods:}

Fresh preparation of $100 \mathrm{ml}$ of $2.5 \%$ trypsin EDTA buffer:

Dissolve 2.5 gram in $50 \mathrm{ml}$ phosphate buffer saline (PBS) and dissolve 0.4 gram EDTA in $50 \mathrm{ml}$ PBS. Add two solutions and liquating into $1 \mathrm{ml} \mathrm{u}$ shaped sterile tubes; store it at $40 \mathrm{c}$ until use.

\section{Preparation of the medium: ${ }^{(13)}$}

The selective media Mitis Salivarius Bacitracin was prepared as following:

Ninety grams of dehydrated Mitis Salivarius agar (Difco) were dissolved in one liter distilled water. The medium was heated to dissolve the components and then autoclaved at $121^{\circ} \mathrm{C}$ for $15 \mathrm{~min}$. The medium was left to cool to $50{ }^{\circ} \mathrm{C}$, then add $1 \%$ potassium tellurite and $1 \mathrm{ml}$ of $20 \mathrm{unit} / \mathrm{ml}$ bacitracin.

Each plate was poured with approximately $25 \mathrm{ml}$ of the medium, then it was stored in refrigerator at $4^{\circ} \mathrm{C}$ until use. The bacteria were counted on the wires by colony forming method.

\section{Preparation of wire samples:}

Patients were instructed not to eat, drink or even brush teeth for about 2 hours before taking the samples. Nitinol (NiTi) half archwire (.018" diameter) is placed on right side of the maxillary arch and ligated to the brackets by elastic O ties. Stainless Steel (SS) half archwire (.018" diameter) was inserted on left side of maxillary arch and ligated to the brackets by elastic ligation. (Split-mouth design).

The patients were instructed to take honey mouth wash twice per day for standardized interval among all patients 3 days, 7 days, 14 days, and 30 days. So the number of samples that taken from each patient were 12 samples including 2 sample (Niti and SS) without honey on 90 minute, then all the 10 samples were done with honey at 90 minute, 3days, 7days, 14days, and 30days for both wires (Niti and SS).

The name of patient, type of wire and time of insertion were written on the labeled Eppendorf 
tubes. After 90 minutes, both arch wires were removed separately from the patient mouth carefully to avoid iatrogenic biofilm dislodgement ${ }^{(14)} .10$ $\mathrm{mm}$ length were measured from the end of the arch wire by metallic ruler, marked by permanent marker and then cut it using sterilized distal end wire cutter.

Each wire sample was placed directly on labeled Eppendorf tubes containing $1 \mathrm{~mL} 2.5 \%$ trypsin EDTA freshly prepared as transport media to keep the bacteria alive until they were transferred to a microbiology laboratory and the wire incubated on it for 45 minute ${ }^{(14)}$. The samples were transported rapidly to the laboratory, Department of Microbiology, Faculty of Medicine, Alazhr University.

\section{Preparations of honey mouth wash:}

Hadramy mountain sidr honey $100 \%$ concentration was used.

\section{Identification of streptococcus Mutans:}

It was placed on agar plate containing Mitis Salivarius agar the selective media for the Streptococcus Mutans ${ }^{(16)}$. The plates were incubated in the candle jar 5-10\% $\mathrm{CO}_{2}$ at $37^{\circ} \mathrm{C}$ for 2-3 days. This allows bacteria to multiply and proliferate. The amount of streptococci was counted by colony forming unit count method.

Suspected pure colonies were identified as streptococcus mutans on Mitis Salivarius agar and catalase reaction. The colony morphology confirmed with control isolate to be sure as streptococcus mutans. The colonies were raised, convex, opaque of dark blue color with rough margins and granular appearance.

\section{Estimation of streptococcus Mutans count:}

Prepare 10 fold dilution of wire solution in sterile saline dilutions were $1.10,1.100,1.1000,1.10000$, $1.100000 .0 .5 \mathrm{ml}$ of each dilution was spread on the surface of the MBS agar. Each sample was cultured in triplicate and the plates were incubated in the candle jar at $37{ }^{\circ} \mathrm{C}, 5-10 \% \mathrm{CO}_{2}$ for 2-3 days.
The bacterial count was calculated by counting the number of colonies/plate and multiplied by the dilution and volume factor.

\section{RESULTS}

Table (1) Comparison of Log 10 bacterial count values recorded at different observation times in all subgroups

\begin{tabular}{|c|c|c|c|c|c|}
\hline & & Mean & Std. Dev. & $\mathbf{F}$ & $\mathbf{P}$ \\
\hline \multirow{12}{*}{ 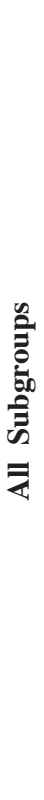 } & St.pre & $4.31^{\mathrm{a}}$ & .67 & \multirow{12}{*}{9.165} & \multirow{12}{*}{$0.00 *$} \\
\hline & St.h.90 min & $3.96^{\mathrm{a}, \mathrm{b}}$ & .71 & & \\
\hline & St.h.3 days & $3.87^{\mathrm{a}, \mathrm{b}}$ & .34 & & \\
\hline & St.h7 days & $3.51^{\mathrm{b}}$ & .33 & & \\
\hline & St.h.14 days & $3.09^{\mathrm{b}}$ & .28 & & \\
\hline & St.h.30 days & $2.40^{\mathrm{c}}$ & .61 & & \\
\hline & Niti.pre & $4.12^{\mathrm{a}}$ & .54 & & \\
\hline & Niti.h.90 min & $3.93^{\mathrm{a}, \mathrm{b}}$ & .47 & & \\
\hline & Niti.h.3 days & $3.73^{\mathrm{a}, \mathrm{b}}$ & .70 & & \\
\hline & Niti.h.7 days & $3.46^{\mathrm{b}}$ & .72 & & \\
\hline & Niti.h 14 days & $2.80^{\mathrm{c}}$ & .46 & & \\
\hline & Niti.h 30 days & $2.30^{\mathrm{c}}$ & .42 & & \\
\hline
\end{tabular}

Significance level P<0.05, *significant

Comparing all subgroups revealed a statistically significant difference between all subgroups $(\mathrm{p}=0.00)$. Tukey's post hoc test revealed no significant difference between SS pre, 90 min, 3 days and Niti pre, $90 \mathrm{~min}$. and 3 days. Moreover, there was no significant difference between St 7 days, 14 days and Niti 7 days. The difference between St 30 days, Niti 14 and 30 days was not statistically significant.

\section{DISCUSSION}

Fixed orthodontic appliances form retentive areas that cause microbial adhesion that cause dental caries and periodontal inflammation. Moreover, its interfere with the efficacy of tooth brushing, reduce the cleaning action of the saliva, change the 
composition of oral flora, and increase colonization of cariogenic and periodontal pathogenic bacteria $^{(15,17)}$.

Nowadays there is great interest in natural medicine. Appropriately, a lot of studies have reported the antibacterial effect natural products against Streptococcus Mutans. Among these natural antibiotics, the unique potential of honey has been documented frequently ${ }^{(18,19)}$.

This choice of this bacterium was in accordance with other previous studies ${ }^{(15,17)}$ that used Streptococcus Mutans in their studies as the main causative of dental caries and periodontal inflammation.

In this study Stainless steel and Nickel titanium arch wires were used because the arch wires obtained from these alloys are the most common aligning and leveling arch wires ${ }^{(15)}$.

In this study Split-mouth design was used (NiTi) half archwire is placed on right side of the maxillary arch while Stainless Steel (SS) half archwire placed on left side of maxillary arch. This design is frequently used in dental clinical research. This design removes a lot of inter-subject variability ${ }^{(20)}$.

In the present study a comparison was done between streptococcus mutans adhesion to stainless steel and nitinol wires after 90 minutes from oral insertion and the results showed that there was a statistically significant difference between both wires $(\mathrm{P}$-value $=0.3117)$. Stainless steel wires showed statistically significantly higher adhesion value in streptococcus mutans count than nitinol wires.

These results were in agreement with the results of an early study that had reported that stainless steel wires have highest surface tension and energy and could have higher plaque retaining capacity, so more bacterial adhesion ${ }^{(21)}$.

Another study was in accordance with the present study which found that Stainless steel wires produce specific changes in the oral environment such as increased plaque accumulation, and elevated Streptococcus mutans colonization ${ }^{(22)}$.

On the other hand in vitro study was done to compare the streptococcus mutans adhesion on different arch wires and the results of this study was in disagreement with the present study in which the NiTi wire showed a significantly higher streptococcus mutans adhesion than the SS wires ${ }^{(23)}$.

In the present study another comparison was done between streptococcus mutans adhesion to stainless steel and nitinol wires before and after using of honey mouth wash and the results showed that a higher mean value was recorded in SS in comparison to SS honey, with a significant difference ( $p=0.047)$. Similarly, a higher mean value was recorded in NiTi in comparison to NiTi honey, with a significant difference $(\mathrm{p}=0.039)$.So there was a reduction on streptococcus mutans adhesion after using honey mouth wash. So honey can be considered as antibacterial agent.

As there is no previous study was found similar to this literature on determining the effect of honey on adhesion of streptococcus mutans to orthodontic arch wires but the previous studies was illustrated the effect of honey as antibacterial agent.

These results were in agreement with previous study that had reported the effects of honey when compared to treatment with either $10 \%$ sucrose or $10 \%$ sorbitol in orthodontic patients. The antimicrobial property of honey was tested against commonly used antibiotics ${ }^{(24)}$.

On the other hand another study was in disagreement with the present study in which their results suggested that honey was as cariogenic as sucrose and increase the number of MS that cause enamel erosion ${ }^{(25)}$

Also this data are not consistent with the results of a previous study that had labeled honey as more cariogenic than sucrose and it was advised that use of honey should be discouraged ${ }^{(26)}$. 
The differences between the results of the present study and the others may relate to the type of honey used, component of the honey and honey sources, differences in registration times, microbiological methods, methodological differences, the oral hygiene level, and the ages of the patients.

\section{CONCLUSION}

Under strict condition of this study it could be concluded that: Streptococcus Mutans adhesion was higher on Stainless steel wires than Nitinol wires. Also honey can be used as a natural antibacterial mouthwash during orthodontic treatment because it was decrease the amount of bacteria.

\section{REFERENCES}

1. Papaioannou W, Gizani S, Nassika M, Kontou E, Nakou M. Adhesion of Streptococcus mutans to different types of brackets. Angle Orthod. 2007; 77:1090-5.

2. Pejda S, Varga ML, Milosevic SA, Mestrovic S. A.Clinical and microbiological parameters in patients with self- ligating and conventional brackets during early phase of orthodontic treatment. Angle Orthod.2013; 83:133-9.

3. Mhaske AR, Shetty PC, Bhat NS, Ramachandra CS. Antiadherent and antibacterial properties of stainless steel and NiTi orthodontic wires coated with silver against Lactobacillus acidophilus-an in vitro study. Progress in Orthodontics .2015; 16:40.

4. Richter AE, Arruda AO, Peters MC, Sohn W. Incidence of caries lesions among patients treated with comprehensive orthodontics. Am J Orthod Dentofac Orthop 2011; 139: 657- 64.

5. Sukontapatipark W, El-Agroudi MA, Selliseth NJ, Thunold K, Selvig KA. Bacterial colonization associated with fixed orthodontic appliances. Eur J Orthod 2001; 23: 475-84.

6. Marsh PD. Dental plaque as a microbial biofilm. Caries Res 2004; 38: 204-11.

7. Kao CT, Ding SJ. Cytotoxicity of orthodontic wire corroded in fluoride solution in vitro. Angle Orthod. 2007; 77:349-54.

8. Mirjalili M, Momeni M, Ebrahimi N, Moayed MH.Comparative study on corrosion behaviour of Nitinol and stainless steel orthodontic wires in simulated saliva solution in presence of fluoride ions. Mater Sci Eng C Mater Biol Appl. 2013; 33:2084-93.
9. Tsai TH, Chien YC, Lee CW, Tsai PJ. In vitro antimicrobial activities against cariogenic streptococci and their antioxidant capacities: a comparative study of green tea versus different herbs. Food Chem 2008; 110: 859-64.

10. Ahmadi-Motamayel F, Hendi SS,Alikhani MY, Khamverdi Z. Antibacterial activity of honey on cariogenic bacteria. J Dent. 2013; 10:10-5.

11. Basson NJ, duToit IJ, Grobler SR. Antibacterial action of honey on oral streptococci. J. Dent. Assoc. S. Afr. 1994; 49:339-41.

12. Wahdan HA. Causes of the antimicrobial activity of honey. Infection 1998; 26:26-31.

13. Tahaa M; El-Fallalb A; Deglac H. In vitro and in vivo biofilm adhesion to esthetic coated arch wires and its correlation with surface roughness. Angle Orthod. 2016; 86: 285-91.

14. Abrahama KS; Jagdishb N; Kailasamc V; Padmanabhand S. Streptococcus mutans adhesion on nickel titanium (NiTi) and copper-NiTi archwires: A comparative prospective clinical study.Angle Orthod. 2017; 87:448-545.

15. Liljemark WF, Okrent DH, Bloomquist CG.Differential recovery of Streptococcus mutans from various mitissalivarius agar preparations. J Clin Microbiol. 1976 Jul; 4:108-9.

16. Yadav NR, Garla BK, Reddy VK, Tandon S, Prasad S. Antimicrobial Effect of Honey on Streptococcus Mutans of Dental Plaque. J Oral Health Comm Dent 2014; 8:72-5.

17. Lee HJ, Park HS, Kim KH, Kwon TY, Hong SH. Effect of garlic on bacterial biofilm formation on orthodontic wire. Angle Orthod. 2011; 81:895-900.

18. Chun MJ, et al.,Surface modification of orthodontic wires with Photocatalytic titanium oxide for its antiadherent and antibacterial properties. Angle Orthodontist2007; 77: 483-8.

19. Bogdanov S, Jurendic T, Sieber R, Gallmann P. Honey for nutrition and health: A review. J Am Coll Nutr 2008; 27:667-89.

20. Zhu H, Zhang S, Ahn C.Sample Size Considerations for Split-Mouth Design. Stat Methods Med Res. 2017; 26: 2543-51.

21. Eliades T, Eliades G, Brantley WA. Microbial attachment on orthodontic appliances. I. Wettability and early pellicle formation on bracket materials. Am J Orthod Dentofacial Orthop. 1995; 108:351-60. 
22. Sug-Joon A, Bum-Soon L, Shin-Jae L. Prevalence of cariogenic streptococci on incisor brackets detected by polymerase chain reaction. Am J Orthod Dentofacial Orthop. 2007; 131:736-41.

23. Kima I; Parkb HS. Comparative short-term in vitro analysis of mutans streptococci adhesion on esthetic, nickel-titanium, and stainless-steel arch wires. Angle Orthod. 2014; 84:680-6.

24. Atwa A, AbuShahba RY, Mostafa M , Hashem MI.
Effect of honey in preventing gingivitis and dental caries in patients undergoing orthodontic treatment The Saudi Dental Journal 2014; 26: 108-14.

25. Bowen WH, Lawrence RA. Comparison of the cariogenicity of cola, honey, cow milk, human milk, and sucrose. Pediatrics 2005; 116:921-6.

26. Konig K, Caries induced in laboratory rats. Post-eruptive effect of sucrose and of bread of different degrees of refinement. Br. Dent. J.1967; 123, 585-9. 